\title{
Effects of Multiple Intelligences Activities on Writing Skill Development in an EFL Context
}

\author{
Zennure Elgün Gündüz ${ }^{1, *}$, İsmail Doğan Ünal ${ }^{2}$ \\ ${ }^{1}$ Faculty of Humanities and Letters, Ardahan University, Turkey \\ ${ }^{2}$ Kazım Karabekir Faculty of Education, Ataturk University, Turkey
}

Copyright $(2016$ by authors, all rights reserved. Authors agree that this article remains permanently open access under the terms of the Creative Commons Attribution License 4.0 International License

\begin{abstract}
This study aims at exploring the effects of multiple intelligences activities versus traditional method on English writing development of the sixth grade students in Turkey. A quasi-experimental research method with a pre-test post-test design was applied. The participants were 50 sixth grade students at a state school in Ardahan in Turkey. The participants were divided as an experimental and a control group randomly. Experimental group was instructed through multiple intelligences activities while the control group was instructed through traditional method. In addition to pre-test and post-test scores, participants' reflections about the methods and their writing experiences during the study were considered in order to arrive at some implications. The findings suggest that the experimental group instructed through multiple intelligences activities showed more improvement from their pre-test to their post-test scores than the control group instructed through traditional method. Experimental group also outperformed the control group according to the post-test scores. In addition, the participants reflected on the multiple intelligences activities more positively than the traditional way of instruction.
\end{abstract}

Keywords English as a Foreign Language, Teaching Writing, Multiple Intelligences, Traditional Method

\section{Introduction}

Foreign language learning is of vital importance in today's globalizing world. Therefore, everyone who has been involved in the process of foreign language teaching tries to find out effective way(s) to be able to teach a foreign language. Consideration of the individual differences while planning lessons is claimed to have utmost importance for an effective instruction. For that end, Multiple Intelligences Theory (MIT) proposed by Howard Gardner in 1983 proposes that each individual is unique and each individual possess his/her her own learning processes. He claims that there are at least eight types of intelligences and individuals differ from each other in terms of their dominant intelligence(s). Therefore, in order to provide students with an effective instruction, the teachers had better address different intelligence profiles of the students. There quite a number of studies related to the effectiveness of MI based instruction in second/foreign language teaching. However, the focus has been basically on grammar teaching and students' attitudes. The number of the studies trying to explore the effects of MI based instruction on skill development in English as a foreign language context in Turkey is limited. The quasi-experimental study presented here examines the effect of MI based instruction, particularly in terms of writing skill development in Turkey. The research question this study sought to answer is: Are there any differences between two groups of participants instructed through traditional method versus multiple intelligences activities in terms of English writing development at the 6th grade level in an elementary state school in Ardahan?

\section{Background}

As a result of the efforts for coming up with an effective way of foreign language teaching, a number of methods have been suggested so far. Grammar-translation method, audiolingualism, direct method, suggestopedia, community language teaching and constructivist method are some of the most notified ones. When the research history and the methods of teaching a foreign language are taken into consideration, it is possible to make a basic classification of methods and techniques such as teacher-centered and learner-centered methods. In teacher-centered method, the teacher is in the centre and $\mathrm{s} /$ he is the most active person in the classroom. His/her basic role is to convey information to the students and be the leader of the classroom. The students are passive and they are expected to take whatever given by the teacher and they are often expected to memorize knowledge. This type of method is often named as traditional 
approach. In the student-centered methods, the students are active and they are expected to bring their prior knowledge and experiences into the classroom and use them in order to construct new knowledge and set up new connections between what they learn and what they already have. During that process, the teacher acts as a mentor or a counselor in order to help the learners construct knowledge within meaningful and purposeful settings.

During the recent years of foreign language research, the tendency has shifted towards more learner-centered methods. It has been accepted that "all students can learn and succeed, but not in the same way and not on the same day." [40]. In order to find the most suitable teaching/learning method/s for the students, learner characteristics and differences are taken into more consideration. When the fact that each individual is different from others and has his/her own characteristics is considered, it can be concluded that language learners are also different from each other and they have different speed and different results in language learning. There are many explanations for that issue. The general factors that influence second language learning are: age, aptitude and intelligence, cognitive style, attitudes, motivation and personality [11]. In recent years, there has been a substantial amount of interest in these individual differences among foreign language learners and intelligence is one of these differences that need to be further investigated. Taking individual differences into consideration lead teachers to be mindful about their students' properties and expectations and make use of techniques and strategies accordingly, this attitude is found to have positive effects on increasing the motivation of the learners. As students' motivation about lessons increase, their level of learning also increases $[19,20,25,30]$. Another important implication suggested by research studies is that although teachers generally accept that students' different intelligence profiles need to be put in the center when lessons are planned and strategies to be followed are determined, in practice they have difficulty in doing so. Therefore, teachers should be also made aware of the ways in implementing MI theory considering the fact that multiple intelligences and foreign language learning have an interactive relationship $[24,35]$

\subsection{Intelligence}

Intelligence is a term that is difficult to define and draw its limits. There have been quite a number of studies that have tried to define what intelligence is and what influences it has on learning, these studies can be traced back to 1900s and Teele [40] proposes that these efforts to try to understand intelligence and its relation to learning can be grouped under four main titles: psychometric approach, developmental progression, the psychobiological approach, and multiple forms of intelligence. In order to propose a framework about how effective learning environments can be developed for students, it is important to provide a brief description of each of them.

\subsubsection{Psychometric approach}

Psychometric approach proposes that intelligence is a single, unitary and measurable concept. Stanford-Binet test developed in 1905 is accepted as the first intelligence tests that claim to measure intelligence. In 1940, Wechlsler scale was developed to measure intelligence. Psychometric scales emphasize only linguistic and logical-mathematical aspects of intelligence $[13,40]$. Spearman proposed a two-factor theory of intelligence. Spearman's two-factor theory states that individual differences in test scores could be attributed to two factors which are called as a general factor, $g$ and specific factor, $s . g$ factor is common to all mental ability measurements while $s$ factor is specific to each and every measurement. In addition, it is asserted that $g$ and $s$ are uncorrelated and various $s$ 's are uncorrelated with each other $[3,21] . \quad g$ factor is considered to be inborn and if an individual's $g$ is high then $\mathrm{s} /$ he is expected to be successful in life and in intelligence tests; $s$ factor is thought to be acquired from environment and an individual's $s$ varies from one activity to another [28, 17]. The basic premise of psychometric approach is that the level of intelligence can be measured through tests which basically involve linguistic and logical-mathematical tasks, and individuals can be compared with each other and classified as intelligent or less intelligent depending on these tests. This approach is criticized for conceptualizing intelligence as only one dimensional entity and disregarding the multifaceted aspects of individuals $[1,3,39,40]$.

\subsubsection{Developmental progression:}

Piaget [cited in 40] suggested that in order to understand intelligence the ways individuals acquire and make use of knowledge need to be explored. He introduced the terms of "assimilation" and "accommodation" in order to explain learning processes. Assimilation refers to incorporation of new knowledge into previous knowledge while accommodation refers to making transformations to the already-possessed knowledge through new experiences or adding new cognitive frameworks to the previous mental frameworks. Piaget proposed that individuals pass through certain developmental stages from infancy towards adulthood, he named these stages as sensorimotor stage of infancy ( $0-2$ years) during which intelligence is related to motor actions; the preoperational (3-7 years) period which can be called as the intuitive stage of childhood; concrete, operational stage (8-11 years) when cognitive structure is reasonable but based on concrete operations; and the formal operational stage of adolescence (12-15 years) during which thinking includes abstractions.

Although Piaget stated that children pass through these stages at specific ages. However, Howard Gardner [14] criticizes Piaget for determining these stages considering only the logical-mathematical thinking competence of the individuals. He states that the picture of development proposed by Piaget is only one sort of development and it ignores the developmental stages of achieving other forms of competence such as competences of becoming and artist, a lawyer or a politician. Studies conducted with children 
suggest that the developmental stages offered by Piaget can differ from one child to another. Teele [40] suggests that "children's developmental progressions of ability depend on the unique combinations of the ways they process information and the different tasks they are given." Therefore, developmental progression of each child is individual, and the fact that $\mathrm{s} / \mathrm{he}$ can achieve a task does not mean that $\mathrm{s} /$ he can achieve another similar task; the unique combinations and individual ways of thinking put forward that developmental progression is a more complex process than simply passing through specific stages at specific ages.

\subsubsection{Psychobiological approach:}

Psychobiological approach to intelligence supported a multi-dimensional view of intelligence instead of defining intelligence as a single factor. Ceci [cited in 39] states that intelligence is a function of the interactions between innate potential abilities, environmental context, and internal motivation. The way a person interacts with their environment determines whether an innate cognitive potential of that person will develop or not. It is claimed that a person's neural connections become stronger if that person stimulate these connections through his/her interactions with environment; however if the neural connections do not get enough stimuli, then they may become weaker and then may disappear. As neural connections become stronger or weaker, a person's related cognitive abilities can become stronger or weaker, as well. It is also mentioned that there may be some critical / sensitive periods during which a person's interactions with environmental resources may be of use and beyond these periods environmental stimulations may not be of use any more. In addition, if a person is motivated to deal with a certain domain of knowledge, then $\mathrm{s} / \mathrm{he}$ will have stronger mental representations about that domain, which can lead to more efficient cognitive processing and retrieval of knowledge in that domain [39].

\subsubsection{Multiple forms of intelligence:}

Sternberg $[38,39]$ proposed a triarchic theory of intelligence. According to this theory, intelligence can be best defined within the framework of a socio-cultural setting as the ways people deal with various situations determine how intelligent those are. The triarchic theory of intelligence has three aspects. First, internal (componential) aspect of intelligence involves information processing skills that are comprised of metacomponents or mental mechanisms that help individuals to solve problems and to acquire knowledge. These components occur in all cultures, however, what is considered an intelligent instantiation of these components may differ across cultures as problems and values vary across cultures. Second, external aspect involves the practical application of the components in the internal aspect to real-world contexts. It is proposed that intelligent people are successful in adapting to a particular environment, if they cannot adapt, then they can find ways to change the environment, and if it is not possible to change the environment, then they know when and how to find or select another environment which is more suitable for them. Third, the experiential aspect of intelligence involves utilizing one's experiences in order to deal with new situations and solve novel problems and automatize the procedures. Intelligent people retrieve and apply relevant information into new situations to cope with the novelty.

Multiple intelligences theory suggested by Howard Gardner is also considered as a complex model of intelligence as it rejects the idea that intelligence is a unitary ability. Gardner [14] defines intelligence as "the ability to solve problems, or fashion products that are of consequence in a particular cultural setting or community." According to Gardner, genetic inheritance, training, socialization in a cultural setting is influential in determining the development of one's intelligence(s). He suggests that there are eight types of intelligences; verbal-linguistic, logical-mathematical, visual-spatial, musical, bodily-kinesthetic, intrapersonal, interpersonal and naturalist. According to MI theory, a person dealing with a task may make use of more than one type of intelligence, that is intelligences can cooperate; however, a person who is strong in one of these intelligences may not be so in another. Therefore, while determining a person as intelligent or not, conventional methods of mental testing cannot give accurate results. Intelligences can be best measured in the contexts in which they occur naturally [14]. When trying to define what intelligence is, the fact that each individual is different from one another as people differ in mental abilities, such as reasoning, memory, speed of information processing, verbal ability, the ability to organize and plan, and so forth [3].

It is possible to make this list of approaches to intelligence longer and it is possible to make classification of the different approaches under different titles. However, a quick survey of the intelligence theories reveals that traditional way of thinking about intelligence views it as a unitary, measurable, constant concept and intelligence is seen as an entity that can be used to classify students and predict their possible success, in addition it is accepted that there is only one intelligence in general. On the other hand, contemporary approaches propose that intelligence can be developed, it is not possible to measure it through tests and define it through numerical values, intelligence can be displayed in many ways and it can be understood in real life situations, intelligence is used to understand the potential strength of individuals [34].

Within the framework of this paper, a contemporary view of intelligence, which multiple intelligence theory proposed by Gardner, will be handled and a quasi-experimental research study trying to explore the effects of multiple intelligences activities on English writing development of the sixth grade students in Ardahan in Turkey will be presented.

\subsection{Multiple Intelligences Theory}

In terms of the role of human intelligence in learning, Gardner [13] proposed the theory of "multiple intelligences." 
He dealt with the concept of intelligence in a different way arguing that intelligence is not restricted by only verbal and mathematical. Howard Gardner preferred not to follow that traditional view of intelligence and in order to get the true meaning of intelligence he decided to consider people who use their intelligence in exceptional ways. Gardner changed the concept of intelligence profoundly because of the way in which he expanded the parameters of intelligent behavior to include a diversity of human abilities $[17,18,36]$. According to Gardner intelligence is "the ability to solve problems or to create products that are valued within one or more cultural settings" [13]. He preferred to add an $-\mathrm{s}$ to intelligence as he broke from the tradition of IQ theory, which previously adhered to two fundamental principles: human cognition was unitary and individuals can adequately be described as having a single, quantifiable intelligence. According to Gardner this traditional view of intelligence was degrading intelligence to a simple faculty. Contrary to this reductionist view of intelligence, Gardner [13,17] defined intelligence as: the skill to solve problems that a person might encounter in real life, the skill to procreate new problems to be solved, and the skill to produce something or suggest a service that is valued within one's culture. MI expands the scope of the concept of intelligence as it also include creative and practical abilities that are associated with each of eight intelligences $[4,9,36]$. Gardner enriched the term intelligence by claiming that all people have different types of intelligences. These intelligences can be strengthened or weakened by means of past experiences and education. Gardner $[13,18]$ suggests that people vary in terms of eight types of intelligence; these are visual, verbal, mathematical, kinesthetic, interpersonal, intrapersonal, naturalistic, and musical intelligence:

\subsubsection{Verbal-linguistic intelligence}

It involves sensitivity to spoken and written language, the ability to learn languages, and the capacity to use language to accomplish certain goals. Lawyers, speakers, writers, poets can be considered to be strong in that intelligence [15]. Lectures, discussions, word games, storytelling, loud / silent reading, writing can be given as examples for the activities related to this type of intelligence $[1,6,8,23,41]$.

\subsubsection{Logical-mathematical intelligence}

It is the capacity to analyze problems logically, carry out mathematical operations, and investigate issues scientifically [15]. Discerning relationships, recognizing abstract patterns, reasoning inductively / deductively are also among the capacities of this intelligence [23]. Scientists, accountants, engineers, computer programmers demonstrate this intelligence [8]. Calculations, number games, critical thinking, using diagrams, graphs, patterning are some of the activities that can be used in relation to logical-mathematical intelligence $[1,6,8,23,41]$.

\subsubsection{Visual-spatial intelligence}

It involves the potential to think in accordance with the patterns of wide or more confined areas [15]. Sculptors, architects, pilots, navigators, graphic artists, chess players are strong in this intelligence. Visual presentations, using visual tools such as paints, pictures, photos, highlighting with color, imagination games, mind-mapping, using charts are among the numerous activities that can take visual-spatial intelligence as the basis $[1,6,8,23,41]$.

\subsubsection{Bodily-kinesthetic intelligence}

This is the potential of using one's body and physical skills. Dancers, actors, athletes, surgeons, mechanics can be said to possess this intelligence $[8,15]$. Drama, dance, games involving movement, physical exercises are among the teaching activities attributed to bodily-kinesthetic intelligence $[1,6,8,23,41]$.

\subsubsection{Musical intelligence}

This intelligence involves a sensitivity to pitch, melody, rhythm, and tone and it also involves skill in performance and composition of musical patterns $[8,15]$. Composers, musicians, instrument makers and sensitive listeners possess musical intelligence. Involving music and rhythm in learning, listening to or singing songs, reading in rhythmic way can be used in relation to musical intelligence $[1,6,8,23,41]$.

\subsubsection{Interpersonal intelligence}

This intelligence refers to the potential in interacting with people effectively and understanding them. Salespeople, teachers, leaders, actors possess interpersonal intelligence $[8,15]$. Cooperative learning, peer tutoring, group work are some of the activities related to interpersonal intelligence $[1,6,8,23,41]$. Using skills related to interpersonal intelligence and cooperating with peer in a language classroom can be claimed to have positive effect on students' language learning [5].

\subsubsection{Intrapersonal intelligence}

It is related to the capacity to understand oneself and plan his/her life in accordance with that understanding. Theologians, psychologists and philosophers possess this intelligence $[8,15]$. Individual acknowledgement, student interest survey, metacognition, engaging feelings in the classroom, individualized instruction, independent study, self esteem building can be counted among the activities related to intrapersonal intelligence $[1,6,8,23,41]$. Students' intrapersonal intelligence can be helped to develop so that they can assess their learning processes and have an insight about learning, which can also improve their learning [5].

\subsubsection{Naturalist intelligence}

It consists of observing patterns in nature, understanding properties of natural systems and the ability to relate to living organisms. Farmers, botanists, ecologists and landscapers are strong in naturalist intelligence [8,23]. Using plants, tolls related to nature, nature study, involving nature in the curriculum, looking closer and observing natural events can be made use of to relate the lessons to naturalist intelligence $[1,6,8,23,41]$. 
Gardner's view of intelligence can be seen as a starting point for teaching English in a way that is different from traditional, teacher centered methods making use of only linguistic intelligence-friendly activities. Preparing lesson plans considering the individual differences and different talents of the students may help the students to focus on the lesson more easily and learn from it more effectively. Gardner's [13] theory of multiple intelligences (MI) proposes a means of understanding how we process, learn, and remember information. His theory asserts that while individuals are capable of processing information in at least eight different ways; each individual varies in the degree of skill possessed in each of these intelligences. He identifies eight categories of skills and abilities which he considers to be individual intelligences: linguistic, logical-mathematical, spatial, bodily-kinesthetic, musical, interpersonal and intrapersonal and naturalistic. He believes that these discrete abilities operate together in complex ways, and provide a much more comprehensive view of what constitutes human intelligence. The theory of multiple intelligences can be a means to address students' diverse intelligences by creating individualized learning environments.

\subsection{Multiple Intelligences and Foreign Language Teaching}

Multiple Intelligence Theory and its applications in the educational settings are growing so rapidly. There is no one definite way through which the theory can be applied in education. The theory is very flexible and it can be adapted to the context in which it is applied. "The theory can be implemented in a wide range of instructional contexts, from highly traditional settings where teachers spend much of their time directly teaching students to open environments where students regulate most of their own learning" [1]. In the type of education that was framed by Gardner's view points; the human individual differences are given primacy to anything else.

The key points of MI are useful to the English language teaching profession as well as to the other domains. It sees the teaching of English as an integrated and holistic experience and aims to teach communicative competence. It helps us understand the diversity in the students and provides a framework for addressing the differences in the teaching process. To base the instruction of the English language on MI Theory means that the teacher should use a variety of teaching strategies which should be used in a way that makes this instruction address the intelligences which the students possess. That is, teachers need to consider how a target system can be presented through different intelligences and how that target system can be translated "into the languages of other intelligences, namely, pictures, physical or musical expression, logical symbols or concepts, social interactions, and intra-personal connections" [1]. Making use of MI activities can help the teachers to embrace all the students and attract their attention to the lesson through involving activities and materials that are suitable for the interests and needs of their students $[10,12,41]$. For that end, teachers need to determine their objective and the topic to be taught, then $\mathrm{s} /$ he needs to determine various strategies and materials so as to address different intelligences of the students, and it can be an alternative to prepare a pool of activities and then select among from these activities, as a last step teacher needs to make his/her plans then apply them in the classroom $[2,4]$. Integration of MI into foreign language teaching enables the language learners to benefit from eclectic, effective, and creative approaches to teaching a foreign or second language [42]. Research studies conducted in various districts with participants from different levels propose that considering multiple intelligences profiles of the students while preparing lessons and trying to involve activities and strategies that address the different intelligences types in classrooms have positive effects on students' attitudes towards lessons and they also effect students' achievement in a positive way when compared with traditional way of instruction involving mere transfer of knowledge, and which does not allow use of games, songs and poems along the lesson [e.g. 5,12,25,37].

\subsection{The case in Turkey}

As English is taught as a foreign language in Turkey and the learners do not have much chance in practicing their foreign language in real-life situations, they encounter difficulties in the process of learning it. In classrooms where the teacher controls the introduction of new language forms, and controlled practice precedes freer communicative use of the new forms, language learning becomes a difficult task [26]. In most cases, the students have difficulty in learning English when it is presented through a traditional way of teaching which disregards the differences among students and makes use of only one type of instruction. This instruction often involves the presentation of the target form, controlled practice of the forms and production again in controlled settings. However, in order to have an effective foreign language teaching, research studies have put forward the fact that the individual differences have to be taken into consideration. Students can benefit more from the methods of instruction in which teachers use different methodologies, exercises and activities to reach all students, not just those who excel at linguistic and logical intelligence with a broader vision of education [1].

In order to have an effective instruction, Turkish Ministry of National Education has also tried to apply different methods. Within this framework, some principles of MI were included in the English language teaching curriculum. Basic Law of National Education no 1739 emphasizes the importance of educating a student according to his/her interests and skills: "The general purpose of the Turkish National Education is to raise all Turkish citizens in line with their own interests and abilities, to prepare them for life by helping them to acquire the required knowledge, skills, behavior and cooperative working habits and to ensure they have a profession which will make them happy and 
contribute to the happiness of society." Therefore, the Ministry of Education's notification related to the course design with Multiple Intelligences Activities has underlined the importance of this theory. However, it is seen that especially in the field of English Language Teaching there is a lack of research related to multiple intelligences theory.

Consequently, this study aims at finding out the effects of the MI activities on the development of writing skill in English. For that end the research question addressed by this study is: "Are there any differences between two groups of participants instructed through traditional method versus multiple intelligences activities in a content-based framework in terms of writing development in foreign language at the 6 th grade?

\section{The study}

\subsection{The Context}

Subjects in this study were sixth-grade students in a state school. The school offered three hours of English lessons per week. Before the research study, the teacher employed traditional way of instruction for both classes.

In terms of the classroom environment, experimental and the control groups had the same physical properties in their classes. The classes had a computer and a projector. Before the research study, both classes were instructed English through traditional method. During the research study, the same teacher continued to instruct at both experimental and control classes; however, the researcher also attended to the classes in order to make observations, take notes about the instructional procedures and students' reactions, attitudes and also in order to provide help for the teacher when necessary.

\subsubsection{Traditional method in the sixth grade English class}

Traditional method was implemented in the control group as before. The unit to be covered during the research was on "comparatives." The researcher did not have any intervention in the English lessons of the control group. The traditional method emphasized the correct usage of the grammar forms. The teacher tried to make the students aware of the grammar rules. The focus of the lessons was on the learning of grammar rules in isolation. Structured exercises were often used in order to reinforce the usage of the target grammar forms. During the reading and writing activities, the teacher tried to attract the attention of the students to the use of grammar rules instead of meaning of the text. For instance, the textbook included comprehension questions following the reading texts, and instead of encouraging the students to give answers that are correct in terms of their content, they were expected to produce answers that were correct grammatically. Another focus of the lessons was vocabulary learning. The teacher introduced most of the target vocabulary items of the unit in isolation and the students were expected to memorize them. The grammar instruction and the correspondences of the vocabulary items were given in the native language of the learners, that is in Turkish. As Richards and Rodgers [33] stated the techniques used in the classroom that employed traditional way of teaching included memorization of dialogs, questions and answer practice, substitution drills and guided speaking and writing practices, fill-in-the-gaps exercises.

\subsubsection{MI-based instruction in the sixth grade English class}

The unit to be covered during the research was on "comparatives" in experiential group, as well. However, in order to cover the target grammar form within a context, the researcher also determined a theme which was "animals." The reason for choosing that theme was the idea that animals could be an interesting subject for the sixth graders; an addition, as the students were also familiar with the topic of animals, it would not place an extra burden on the students. Multiple intelligences activities were implemented in a content-based setting in the experimental group. The use of MI activities aimed at reaching all the students who had different intelligence types and therefore different learning styles. The researcher had meetings with the teacher before the language lessons and they talked about what to do during the lesson. The researcher explained the procedures to be followed during the lesson. It should be also stated that the researcher took the opinions of the teacher into consideration and made some changes in the lesson plans when necessary. The teacher was provided with the materials before the lesson and she explained how to implement those materials. As the teacher was already familiar with MI theory and had some in-service training on that subject, she did not have any difficulties in implementing the materials and conducting the activities. Each English lesson involved implementation of two or three MI activities because the duration of the classes was not enough to carry out at least eight activities addressing all of the eight types of intelligences. Examples from the MI activities implemented in the experimental groups can be listed as following: vocabulary games, word-search puzzles, reading, writing activities (verbal-linguistic intelligence); puzzles and games, matching exercises, classifications and categorizations (logical-mathematical intelligence); power point presentations, flashcards, pictures (visual-spatial intelligence); miming games, hands-on activities (bodily-kinesthetic intelligence); playing music, composing a song, singing (musical-rhythmic intelligence); pairwork, group work (interpersonal intelligence); writing one's own feelings and thought on a piece of paper, reflecting on one's own learning (intrapersonal intelligence); bringing some objects from natural life, bringing realia into the classroom (natural intelligence). In order to prepare MI based activities, the researcher was inspired by some writers [e.g., 7,8,10,13-16,23,34,41].

The teacher and the researcher aimed at teaching target vocabulary and the target grammar form, however the focus of the lessons was not on structures only. The teacher tried to teach them within a context and through content. For 
example, when the topic was comparatives, the teacher asked the students to match the adjectives with the related pictures. During such an activity the emphasis was on content and on the matching exercise which seemed to be a game for the students. However, at the same time the students found a chance to learn or at least become familiar with some new vocabulary items within a context. Instead of giving the vocabulary items as a list and in isolation and expecting the students to memorize them, the researcher tried to introduce them within a context and through different activities. For example, she made use of power point presentations, flashcards to introduce new vocabulary items and prepared activities such as word puzzles, games or writing a short sentence or aa short paragraph using newly learned vocabulary items so that the Ss had chance to use vocabulary within a meaningful and purposeful setting which enabled them to learn and remember more easily.

\subsection{Methodology}

The present study was a quasi-experimental one with a pre-test $\&$ post-test design. To this end, participants were assigned to the experimental and control groups randomly. In order to investigate the effects of incorporating MI activities into foreign language lessons on writing development, the participants were asked to write short essays as a pre-test and post-test. On both tests, they were provided with writing prompts and pictures. The pre-test was given to the both groups at the beginning of the study. After the pre-test, the control group was instructed through traditional method and the experimental group was instructed through MI based activities. The implementation process of the methods lasted for three weeks. Both groups had three hours of English lesson per week; therefore the implementation lasted for nine hours of English. The duration of the implementation process was determined considering the time allocated for the target unit in the curriculum. After the implementation process, the participants in both groups were given post-test writing.

\subsection{Participants}

The participants comprised of 50 students of English in sixth-grade classes in a state elementary school in Turkey. They had been assigned randomly to their class groups. The school administration stated that they formed the classroom in a way they tried to make them equal to each other in terms of the number of the students, number of the female and male students, and their academic success during primary school, their socio-demographic characteristics. The researcher determined the experimental and the control groups randomly. Both classes consisted of 25 students. The students had been exposed to English for three years and they were exposed to English for three hours a week during the study. Their native language was Turkish. Their level of English was stated to be beginners' level by their teacher. The students were at the age of 11-12. In terms of socio-demographic properties, it was observed that most of the students' families lived in the villages of Ardahan as they were farmers. Therefore, most of the students travelled from their villages to the school every day. Their level of income was not so high and they did not have opportunities to be able to learn English outside the school. Most of the students' parents were primary or elementary school graduates and only a few had parents who graduated from a high school or a university and worked as officials. The students spent most of their time in the school and went back their homes after school; they did not have an active social life.

\subsection{Instruments and Data Analysis}

In order to find out whether there were any differences between two groups of participants instructed through traditional method versus multiple intelligences activities in a content-based framework in terms of writing development in foreign language at the 6 th grade, the participants were asked to write two essays as a pre-test and post-test. The topics of the essays were related to the units covered in the lesson (animals). The students were provided with writing prompts and they were asked to write an essay with an introduction, development and conclusion parts. An essay evaluation rubric developed by Reid [32] was used to evaluate the essays. Apart from the researcher, the essays were also blind-rated by two experts who were also English teachers using the same rubric in order to have an objective evaluation. The maximum possible score was 100 . Inter-rater reliability coefficients for two sets of essays were 0.82 and 0.85 . In order to interpret quantitative data, the researcher also tried to collect qualitative data through observations throughout the research process. After pre and post tests, the researcher interviewed with ten students randomly selected among participants. During the interviews, the researcher asked the students about their writing experience. The researcher tried to find out the points at which the students had difficulties or at which they enjoyed the writing task.

In addition to the data collected through pre and post tests, and interviews, demographic information related to the participant was collected through five open-ended questions.

\subsection{Results and Discussion}

In order to find out whether there were any differences between pre-test and post-test scores within the same group, paired samples t test was applied on essay scores for two groups separately. In addition, in order to find out whether there were any differences between the post test scores of experimental and control groups, independent samples $t$ test was applied on the post-test scores of both groups. The findings were interpreted within the framework of the researcher's observations and the interviews conducted with the students. 
Table 1. Descriptive Statistics for Pre-test and Post-test Scores on Writing

\begin{tabular}{|c|c|c|c|c|c|}
\hline Test & Group & $\mathrm{N}$ & Mean & $\begin{array}{c}\text { Std. } \\
\text { Deviation }\end{array}$ & $\begin{array}{c}\text { Std. } \\
\text { Error } \\
\text { mean }\end{array}$ \\
\hline \multirow{2}{*}{$\begin{array}{c}\text { Writing } \\
\text { pre-test }\end{array}$} & $\begin{array}{c}\text { Experimental } \\
\text { group }\end{array}$ & 25 & 31.48 & 6.20 & 1.24 \\
\cline { 2 - 6 } & Control group & 25 & 30.40 & 9.34 & 1.86 \\
\hline \multirow{2}{*}{$\begin{array}{c}\text { Writing } \\
\text { post-test }\end{array}$} & $\begin{array}{c}\text { Experimental } \\
\text { group }\end{array}$ & 25 & 51.80 & 16.00 & 3.20 \\
\cline { 2 - 6 } & Control group & 25 & 31.20 & 8.69 & 1.73 \\
\hline
\end{tabular}

When the descriptive statistics presented in the Table 1 are investigated, it can be seen that the writing scores of the control and experimental groups were similar at the beginning of the research study.

Table 2. Independent Samples t-test Results on Pre-test Scores of Both Groups

\begin{tabular}{|c|c|c|c|c|c|}
\hline Group & Mean & $\begin{array}{c}\text { Std. } \\
\text { Deviation }\end{array}$ & $\mathrm{t}$ & $\mathrm{df}$ & $\mathrm{p}$ \\
\hline Experimental & 51.80 & 16.00 & \multirow{2}{*}{.481} & 48 & .63 \\
\hline Control & 31.20 & 8.69 & & & \\
\hline
\end{tabular}

In order to determine whether the differences between pre-test scores of the students in the control and experimental groups were significant or not, independent samples t-test was applied on the pre-test scores of both groups. The results presented in Table 2 indicated that there was no significant difference between groups in terms of pre-test scores on writing ( $p>.05)$. Therefore, it could be concluded that the groups were similar at the beginning of the research in terms of their writing level in L2, and any differences between the two groups after the research could be attributed to the implementation of two different methods.

Before finding out whether there were any differences between two groups on their post-test scores, the pre and post test scores of each group were compared within the group itself in order to see whether the group showed ant development from pre-test to the post test.

Table 3. Paired Samples t-test Results for Control Group on Pre-test and Post-test Scores

\begin{tabular}{|c|c|c|c|c|c|c|}
\hline & $\mathrm{N}$ & Mean & $\begin{array}{c}\text { Std. } \\
\text { Deviation }\end{array}$ & $\mathrm{df}$ & $\mathrm{t}$ & $\mathrm{p}$ \\
\hline Pre-writing & 25 & 30.40 & 9.34 & \multirow{2}{*}{24} & -1.072 & .29 \\
\hline Post-writing & 25 & 31.20 & 8.69 & & \\
\hline
\end{tabular}

When Table 3 is investigated, it can be seen that control group, that is the group instructed through traditional method, showed a slight improvement when the pre-test and post-test means are considered. However, this slight difference was found to be non-significant $(\mathrm{p}>.05)$. As a result, it may be suggested that traditional way of instruction was not much effective in improving the students' L2 writing skill.

Table 4. Paired Samples t-test Results for Experimental Group on Pre-test and Post-test Scores

\begin{tabular}{|c|c|c|c|c|c|c|}
\hline & $\mathrm{N}$ & Mean & $\begin{array}{c}\text { Std. } \\
\text { Deviation }\end{array}$ & $\mathrm{df}$ & $\mathrm{t}$ & $\mathrm{p}$ \\
\hline Pre-writing & 25 & 31.48 & 6.20 & \multirow{2}{*}{24} & -5.97 & .000 \\
\hline Post-writing & 25 & 51.80 & 16.00 & & \\
\hline
\end{tabular}

When the analyses on pre-test and post-test scores of experimental group is considered as shown in Table 4, it can be noticed that the post test scores of the experimental group were higher that the pre-test scores. Paired samples t test analysis put forward that the difference between pre-test and post-test scores of experimental group was significant $(p<.05)$. This finding may suggest that MI activities implemented in a content-based framework were effective in helping the students to improve their writing skill, at least on a topic covered in the lessons.

As the study investigated whether there was a significant effect of the instructional types (MI-based activities and the traditional method) on writing development, independent samples $t$ test analysis was conducted on the post-test scores of experimental and control groups. The results are given in Table 5.

Table 5. Independent Samples t-test Results on Post-test Scores of Both Groups

\begin{tabular}{|c|c|c|c|c|c|}
\hline Group & Mean & $\begin{array}{c}\text { Std. } \\
\text { Deviation }\end{array}$ & $\mathrm{t}$ & $\mathrm{df}$ & $\mathrm{p}$ \\
\hline Experimental & 51.80 & 16.00 & \multirow{2}{*}{5.65} & 48 & .000 \\
\hline Control & 31.20 & 8.69 & & \\
\hline
\end{tabular}

As presented in Table 5, the results put forward that there was a significant difference between the post-test scores of the control group and those of the experimental group on writing test $(\mathrm{t}=5.65, \mathrm{df}=48, \mathrm{p} \leq 0.00)$. This suggests that there were differences between the performances of the students in the experimental group and control group after the educational treatment. When the mean scores of both groups on writing test are compared, it can be seen that this difference is in favor of the experimental group. While the means for the experimental group was 31.48 in pre-test and 51.80 on post-test, the means for the control group was 30.40 in pre-test and 31.20 on post test. Therefore, the analyses conducted on the pre and post-tests of both groups yield that MI-based activities were found to be more effective than the traditional way of instruction in enabling the sixth grade students to write in a more effective way within the framework of the present research.

When the results of the present study are considered within the framework of the interviews conducted with the participants, it may be possible to arrive at some inferences for the rationale behind the findings. After the implementation of the pre-test writing, some students were asked about their writing experiences and they were required to comment on the aspects that made their writing process easy or difficult. The fact that in traditional method, the students were not taught English in a context and they were required to memorize some grammar rules and vocabulary in isolation made it difficult for them to transfer their knowledge into writing. Some students suggested:

"I know the rules, but I don't know how to make sentences in a meaningful order."

"I can say some words about the pictures given to us, but it is difficult for me to write an essay making use of the pictures." 
The students can memorize the rules or the vocabulary items; however, they cannot use them within a context to deliver a meaningful message. They see English lesson as a mechanical lesson, instead of seeing it as a means of communication in another language.

Traditional way of instruction presents the foreign language as if it was a math lesson. The rules are given and sentences are made in accordance with these rules. However, such a one-way-of-instruction prevents the teachers from addressing many students and teaching them English in an effective way. There was no "plasticity" in lessons instructed in traditional method, which could have enabled the teachers to reach students with different intelligence profiles and enliven their desire to learn and use language. It could be observed that in the control group where traditional method was applied, the students became bored easily and they lost their interest in the lesson. Therefore, it became difficult for the students to develop their language skills including writing. The case was similar after the post-test writing in control group. The students complained about not being able to understand English and use it. Most of them were already convinced that they could not understand English, therefore they could not write anything. Some of them even thought that they did not have the skill to learn a language:

"I don't understand anything in English lessons. I'm not so capable, I think."

"I can memorize the rules, but I can easily forget them. I always mix a rule with the other one."

"It is difficult to memorize words. Even if I memorize words, this time I cannot make sentences."

The basic reason underlying such statements may be the fact that the students had been offered English lesson always in one way although each and every student is unique and have ways of learning that are particular to them. Efforts that try to make the students to learn a foreign language through one or two specific ways may not be enough to embrace all the students in a classroom.

The students in the experimental group were also interviewed after the implementation of MI-based activities and after the post-test writing. The students said they the lessons instructed through MI-based activities were more interesting and enjoyable for them. Therefore, they could pay attention to the lessons and learn more easily. Some students stated:

"We were involved in many activities. Some activities were very enjoyable, particularly the games. I was not bored and I would like to learn English in that way (through MI based activities)."

"We actually learn the same topic but we learn it in many ways, so repeat it again and again. So I don't forget it."

"I learn the meaning of words easily, because I use it again and again in games, in puzzles. And I try to use words to write sentences, to prepare role plays."

The MI-based activities seemed to help the students learn and retain whatever they learn and use it when necessary. As Lazear [23] states, integrating multiple intelligences activities can help the students to develop the full range of their potential intelligences and ensure a deeper and a more thorough understanding of the material that is taught and as a result, it becomes easier for them to use it later. It is also clear from the statements of the students that what they learn does not remain in their books or in their notebooks. They seem to internalize what they learn instead of memorizing and forgetting in a short time. When the results of the present study are considered as whole, it can be concluded that multiple intelligences based activities evoked positive reflections in the participants and those activities had positive effects on writing development of the participant within the framework of the present research. These findings are consistent with the previous research studies [e.g., $5,12,22,24,25,29,31]$.

The observations of the researcher are also in line with what the students stated, the students were motivated to be involved in various activities, and this motivation helped to increase learning. When an activity was finished they were in expectation of the following one instead of getting bored or uninterested in the lesson. This excitement may be related to the idea that each and every student found something appealing to him/her in the lessons conducted through MI-based activities [1]. A linguistic activity may not be interesting for one student, but a visual one may grasp his/her attention, or musical activities may not be so interesting for another, however bodily-kinesthetic activities may enliven his/her interest for the lesson. On the other side, the one way of teaching applied in the traditional method, which is usually linguistic or mathematical activity, may not be enough to attract the attention of all the students throughout the lesson. It can be difficult even for a verbal/linguistic child not to lose his/her interest in lesson when $\mathrm{s} / \mathrm{he}$ is continuously exposed to the verbal/linguistic activities in the same form throughout the lesson.

\section{Conclusions}

This study attempted to explore the effects of multiple intelligences activities on writing development of the sixth grade students in Turkey. The results of the study suggest that the experimental group instructed through multiple intelligences activities showed more improvement from their pre-test to their post-test scores than the control group instructed through traditional method. When the mean scores of the both experimental and control group on post-test were considered, it was also found out that experimental group outperformed the control group. These findings suggest that MI-based activities were more effective than the traditional way of instruction in enabling the students to write in a more effective way. The basic reason for that finding can be the idea behind MI Theory, which considers each learner as a 
"unique" person and suggests that all children have different inclinations in the eight intelligences $[1,14]$. As MI theory sets the basis for the use of different techniques in the classroom, teachers do not limit themselves to only one way of instruction; as a result they can reach more students through different ways. This process then can be expected to increase level of learning.

The participants' positive attitudes towards MI-based activities also support the quantitative findings. They found the MI-based activities more motivating, more enjoyable, and more interesting than the traditional way of instruction. This positive attitude can also enable to increase their interest in the lesson and internalize what they learn and use it automatically when necessary.

The findings of the study have certain implications for English language teaching, as well. As Lazear [23] states, teachers had better not try to cover everything in their lessons as this leads to superficial learning, which is easily forgotten. Instead, a thorough covering of the target stuff can lead to real learning and this can be achieved through integrating M1-based activities in the curriculum. Different activities addressing different intelligences can enable teaching the same stuff in different ways and reaching most of the students and helping them understand the lesson. Moreover, MI theory suggests that teachers make use of a larger repertoire of techniques, tools and strategies beyond the typical linguistic and logical ones [2]. As they involve more tools and techniques, they can reach more students and this can lead to more effective teaching. In addition, while planning curriculum and lesson plans, individual differences in intelligence profiles of the students need to be taken into consideration. Instead of trying to teach everything through traditional linguistic and logical techniques, the techniques and the strategies to be implemented in the classrooms need to be varied. This variety in techniques and tools can be expected to lead to real learning of the target stuff rather than mere memorization.

Although the present study is of importance in terms of the results and the implications it suggest, it has also certain limitations. Although the number of the participants was enough for the current research as it was a case study, in order to arrive at more accurate and generalizable results, similar studies can be conducted with a larger number of participants. Another limitation can be that during the present study, only one unit was taken as a basis and the writing development was measured taking the stuff covered in that particular unit. In order to understand the effects of both MI-based activities and the traditional method on writing development in a wider perspective, the time duration of the research can be lengthened and the effects can be measured in longer time period. In addition, in the present study one pre-test and one post-test was administered. Some other measurement tools such as writing tests requiring the students to combine sentences, write paragraphs, dialogues, another essay can also be used to collect more data on the effects of the methods implemented. Moreover, the number of the students interviewed was only ten, which can be seen enough when the total number of the participants is considered. However, in order to have a clearer picture about the attitudes of the students towards both methods, more students need to be interviewed. In addition to interviews, questionnaires, open-ended questions can also be used. Despite its limitations, this study can be considered one of the many steps that need to be taken in order to plan curricula taking the different intelligence profiles of the students into consideration and embrace all the students no matter how different they are from each other.

\section{REFERENCES}

[1] Armstrong, T. (1999). 7 Kinds of smart: identifying and developing your own intelligences. New York: Plume Books.

[2] Armstrong, T. (2000). Multiple intelligences in the classroom. Alexandria, VA: ASCD.

[3] Bartholomew, D., Allerhand, M., Deary, I. (2013). Measuring mental capacity: Thomson's bonds model and Spearman's g-model compared. Intelligence 41(4), 222-233.

[4] Baş, G. (2014). Evaluation of multiple intelligences based instruction in English course from the views of students. Kastamonu Journal of Education 22(1), 177-201.

[5] Behjat, F. (2012). Interpersonal and intrapersonal intelligences: Do they really work in foreign language learning? Procedia-Social and Behavioral Sciences 32, 351-355.

[6] Berman, M. (2002). A multiple intelligences road to an ELT classroom. UK: Crown House Limited.

[7] Bümen, N. (2005), Okulda Çoklu Zekâ Kuramı, Pegem Yayıncılık: Ankara.

[8] Campbell, B. \& Campbell, L. \& Dickinson D. (1999). Teaching and learning through multiple intelligences. USA: Allyn \& Boston.

[9] Davis, K., Christodoulou, J., Seider, S., and Gardner, H. (2012). The theory of multiple intelligences. In Sternberg, R. J., Kaufman, S. B. (Eds.). The Cambridge handbook of intelligence (485-503). Cambridge University Press: UK.

[10] Demirel, Ö., Başbay, A. and Erdem, E. (2006). Eğitimde Çoklu Zeka Kuram ve Uygulama, Ankara: PegemA Yayıncılık.

[11] Ellis, R. (1994). The study of second language acquisition. China: Oxford University Press.

[12] Firozjaei, A. K., Khakpour, F., Naseri, M., Maleknia, A. S. (2013). Learning behavior, English learning and multiple intelligences. International Journal of Psychology and Behavioral research 2(2), 91-100.

[13] Gardner, H. (1983). Frames of mind: the theory of multiple intelligences. New York: Basic Books.

[14] Gardner, H. (1993). Multiple intelligences: the theory in practice - a reader. New York: Basic Books.

[15] Gardner, H (1999). Intelligence reframed: multiple 
intelligences for the 21 st century, New York: Basic Books.

[16] Gardner, H (2006). Who owns intelligence? In Gardner, H. (Ed.), The development and education of the mind. The selected works of Howard Gardner (63-74). Oxon, England: Routledge.

[17] Gardner, H. (2011b). The theory of multiple intelligences: As psychology, as education, as social science. Retrieved from http://www.pz.harvard.edu/sites/default/files/The\%20Theory $\% 20$ of $\% 20 \mathrm{MI} \% 20-\% 20 \mathrm{As} \% 20$ Psychology....pdf on 02.06 .2016

[18] Garner, H. (2013). Frequently asked questions - Multiple intelligences and related educational topics. Retrieved from https://howardgardner01.files.wordpress.com/2012/06/faq m arch2013.pdf on 06.06.2016.

[19] Ibnian, S. S. K., Hadban, A. D. (2013). Implications of multiple intelligence theory in ELT field. International Journal of Humanities and Social Science, 3(4), 292-297.

[20] Jee, M. J. (2014). Affective factors in Korean as a Foreign Language: anxiety and beliefs. Language, Culture and Curriculum, 27(2), 182-195, DOI: $10.1080 / 07908318.2014 .918626$

[21] Jensen, A: R. (1998). The g Factor: The Science of Mental Ability. USA: Praeger Publishers

[22] Johnson, M. (2007). An Extended Literature Review: The Effect of Multiple Intelligences on Elementary Student Performance, Unpublished MA Thesis, Dominican University of California.

[23] Lazear, D. (2000). The Intelligent Curriculum: Using MI to Develop Your Student's Full Potential, New York: Zephyr Press.

[24] Leckron, L. L. (2013). Implementing Gardner's theory of multiple intelligences at the college level of learning. Unpublished PHD dissertation, Capella University.

[25] Maftoon, P. (2012). The realization of gardner's Multiple intelligences (MI) theory in second language acquisition (SLA). Journal of Language Teaching and Research, 3 (6), 1233-1241.

[26] Newton, J. (2001) Options for vocabulary learning through communication tasks. ELT Journal Vol.55/1 January 2001: Oxford University Press

[27] Nijenhuis, J., Hoek, M., Armstrong, E. L. (2015). Spearman's hypothesis and Amerindians: A meta-analysis. Intelligence, 50, 87-92.

[28] Pal, H.R. and Pal, P. T. (2004). Theories of intelligence.
Everyman's Science, 39 (3), 181-186.

[29] Pekderin, S. (2006). The Effectiveness of Multiple Intelligence Activities on Vocabulary Learning in Elementary Classes, Unpublished MA Thesis, Çanakkale On Sekiz Mart University, The Institute of Social Sciences.

[30] Pishghadam, R., Khajavy, G. H. (2013). Intelligence and metacognition as predictors of foreign language achievement: A structural equation modeling approach. Learning and Individual Differences, 24, 176-181.

[31] Pociask, A. and Settles, J. (2007). Increasing Student Achievement through Brain-Based Strategies, Unpublished MA Thesis, Saint Xavier University

[32] Reid, J. (1993). Teaching ESL Writing. New Jersey: Prentice Hall Regents

[33] Richards, J. and Rodgers, T. (1990), Approaches and Methods in Language Teaching, 6th Ed., Cambridge: Cambridge University Press.

[34] Saban, A. (2001). Çoklu zekâ teorisi ve eğitimi. Ankara: Nobel Yayınları.

[35] Savaş, Perihan (2012). Pre-service as a foreign language teachers' perceptions of the relationship between multiple intelligences and foreign language learning. Learning and individual differences, 22, 850-855.

[36] Shearer, C. B. (2012). An inter-rater reliability of a self-assessment for the multiple intelligences. International Journal of Psychological Studies, 4(3), 131-138.

[37] Stăncună, L. A., Crăciun, A. I. (2011). A multiple intelligences approach: intuitive English learning - a case study for k-1 students. Procedia Social and Behavioral Sciences, 11, 72-76.

[38] Sternberg, R.J. (1985). Beyond IQ: A triarchic theory of human intelligence. New York: Cambridge University Press.

[39] Sternberg, R. J. (2000). The concept of intelligence. In R. J. Sternberg (Ed.), Handbook of Intelligence (3-16). USA: Cambridge University Press.

[40] Teele, S. (2000). Rainbows of Intelligence: Exploring how students learn. California: Corwin Press, INC.

[41] Weber, E. (2005). MI Strategies in the Classroom and Beyond. USA: Pearson Education, Inc.

[42] Weber-Segler, E. (2013). Multiple intelligences theory and foreign language education: Perspectives of college students in a German immersion program. Unpublished PHD dissertation, Capella University. 